Subscriber access provided by Universitätsbibliothek Bern

Contaminants in Aquatic and Terrestrial Environments

\title{
A high-resolution historical record of plant protection products deposition documented by target and nontarget trend analysis in a Swiss lake under anthropogenic pressure
}

Aurea C. Chiaia-Hernández, Paul Zander, Tobias Schneider, Sönke Szidat, Ronald Lloren, and Martin Grosjean

Environ. Sci. Technol., Just Accepted Manuscript • DOI: 10.1021/acs.est.0c04842 • Publication Date (Web): 17 Sep 2020

Downloaded from pubs.acs.org on October 5, 2020

\section{Just Accepted}

"Just Accepted" manuscripts have been peer-reviewed and accepted for publication. They are posted online prior to technical editing, formatting for publication and author proofing. The American Chemical Society provides "Just Accepted" as a service to the research community to expedite the dissemination of scientific material as soon as possible after acceptance. "Just Accepted" manuscripts appear in full in PDF format accompanied by an HTML abstract. "Just Accepted" manuscripts have been fully peer reviewed, but should not be considered the official version of record. They are citable by the Digital Object Identifier (DOI®). "Just Accepted" is an optional service offered to authors. Therefore, the "Just Accepted" Web site may not include all articles that will be published in the journal. After a manuscript is technically edited and formatted, it will be removed from the "Just Accepted" Web site and published as an ASAP article. Note that technical editing may introduce minor changes to the manuscript text and/or graphics which could affect content, and all legal disclaimers and ethical guidelines that apply to the journal pertain. ACS cannot be held responsible for errors or consequences arising from the use of information contained in these "Just Accepted" manuscripts. 
1 A high-resolution historical record of plant protection products 2 deposition documented by target and nontarget trend analysis in a 3 Swiss lake under anthropogenic pressure 4

Aurea C Chiaia-Hernández ${ }^{1 *}$, Paul D. Zander ${ }^{1}$, Tobias Schneider ${ }^{2}$, Sönke Szidat ${ }^{3}$, Ronald

Lloren $^{4}$, and Martin Grosjean ${ }^{1}$

9 Switzerland

$10{ }^{2}$ Climate System Research Center, Department of Geosciences, University of Massachusetts 11 Amherst, USA

$12{ }^{3}$ Department of Chemistry and Biochemistry and Oeschger Centre for Climate Change 13 Research, University of Bern, Switzerland

$14{ }^{4}$ Eawag, Swiss Federal Institute of Aquatic Science and Technology, Switzerland

$16 *$ Corresponding author

17 Hallerstrasse 12, 3012 Bern, Switzerland; phone +41 (0) 316315518

18 email: aurea.hernandez@giub.unibe.ch. ORCID ID (0000-0001-7148-7336)

19 Paul D. Zander (0000-0001-7340-4768)

20 Sönke Szidat (ORCID ID: 0000-0002-1824-6207)

21 Martin Grosjean (ORCID ID: 0000-0002-3553-8842)

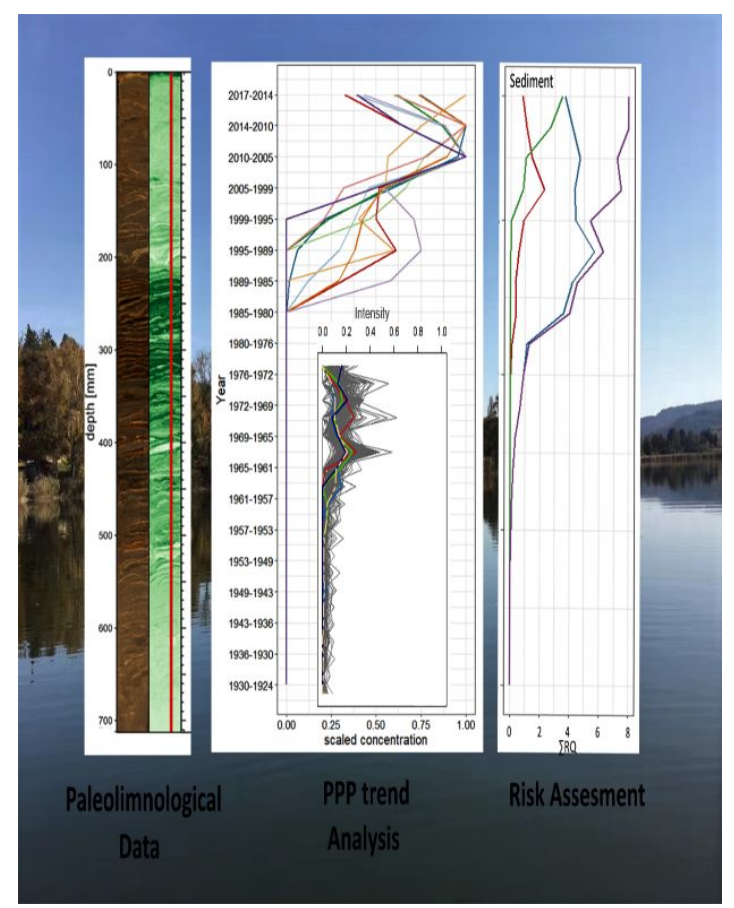




\section{Abstract}

A multiproxy-workflow was used to assess $>60$ plant protection products (PPP) in sediment samples from a Swiss lake under heavy agricultural pressure. The results show the appearance of PPP for the first time in the early 1960s with an overall detection of 34 PPP and with herbicides and fungicides found in equal proportions. Paleolimnological data (e.g., chronology, hyperspectral imaging of sedimentary green pigments and semi-quantitative elemental composition ( $\mu$ XRF scans)) suggest that PPP concentrations and fluxes to the sediment over time are not related to land surface processes such as soil erosion or lake biogeochemistry but are attributed mainly to PPP application (inferred from sales) or regulatory measures (bans). Additional compounds with similar sources of contamination as the target PPP captured by nontarget trend analysis ( $\geq 2000$ unknown profiles), reveal significant inputs of contaminants to the lake starting in the $1970 \mathrm{~s}$, followed by a decrease of contamination at the beginning of the 1990 s and a constant increase by $\sim 28 \%$ of the unknown compounds since the year 2000 . An ecological risk assessment conducted on detected PPP indicates that since the 1980s the sediment quality is insufficient with risk quotients values displaying maximum levels in the most recent sediments ( 2010), despite bans of specific PPP and environmental regulations.

\section{Introduction}

Since the 1960s, application of plant protection products (PPP) increased significantly with the introduction of synthetic insecticides such as organophosphate insecticides in the 1960s, carbamates in 1970s, pyrethroids in 1980s, and the introduction of herbicides and fungicides in the late 1960s-1980s. ${ }^{1}$ For instance, the proportion of herbicides in PPP consumption rapidly increased from $20 \%$ in 1960 to $48 \%$ in $2005 .^{2}$ Prior to the $1980 \mathrm{~s}$, there was relatively little concern that water resources could be contaminated with PPP. ${ }^{3}$ While significant advances have been made in controlling point-source pollution (e.g., wastewater treatment plants (WWTP)), less progress has been made regarding non-point-source pollution (e.g., land runoff, drainage, seepage, spray drift, atmospheric deposition) due to challenges related to the seasonality, inherent variability and multiplicity of origins of non-point sources. ${ }^{3,4}$ Assessing the fate of PPP in the environment is challenging due to the large variety of properties and applications of PPP across space and time, different transport mechanisms through environmental compartments and depositional processes. Once released into the environment, PPP may undergo different courses (e.g. sorption or degradation) or persist due to their very slow degradation, or "pseudo-persist" due to their continuous release into the environment at rates exceeding degradation rates..$^{5}$ PPP have been studied for decades in different matrices (e.g., 
plants, food and water $)^{6-8}$ but surprisingly, not much is known about PPP contamination of lake sediments, largely due to the complexity of sediment analysis and the missing link to paleolimnological methods to obtain good chronologies and to investigate depositional changes over time. Equally, information on toxic effects of organic contaminants in sediments and sediment quality assessments at the international level are lacking, even though sediments serve as habitats and spawning sites for many organisms.

Recently, advances in analytical instrumentation like high-resolution mass spectrometry (HRMS) have opened opportunities to provide a comprehensive overview of the occurrence of organic contaminants and their trends over time by using full spectrum mass spectrometry and nontarget MS analysis. ${ }^{9}, 10$ So far, few studies have investigated systematically different PPP classes simultaneously, nor documented the time when PPP appeared in the environment, or explored their change over time as a response to different management practices or environmental changes. Therefore, the objectives of this work were i) to develop an analytical method to study PPP in lake sediments and to reconstruct sedimentary PPP contamination patterns over the last $\sim 90$ years in a lake under strong agricultural pressure, ii) to use paleolimnological methods as a complementary tool to better understand the depositional system and provide context for the sedimentary records, iii) to assess the ecological risk posed by the detected PPP, and iv) to use nontarget trend analysis to investigate additional contaminants with similar physicochemical characteristics and input sources of contamination as target PPP.

\section{Methods}

\section{Study site and sampling collection and preservation}

Lake Moossee $\left(47.0238^{\circ} \mathrm{N}, 7.4775^{\circ} \mathrm{E}\right)$ is an eutrophic and dimictic postglacial lake located 8 $\mathrm{km}$ north of the city of Bern, Switzerland (Fig. S1). The lake surface is 21.1 ha with a maximum depth of $22 \mathrm{~m}$. The catchment area of Lake Moossee covers $22 \%$ forest, $6 \%$ settlement, $11 \%$ unproductive area, $2 \%$ lake, and 59\% agriculture. ${ }^{11}$ The most important crops grown around the area are (in decreasing order): cereals, corn, sugar beet, potatoes, oilseed rape, orchards, vegetables and vines. ${ }^{8}$ Moreover, Lake Moossee is surrounded by a golf course and swimming recreational area (Fig. S1) located east and west of the lake, respectively.

In October 2017, a $72 \mathrm{~cm}$ (MOOS-17-D) and an $84 \mathrm{~cm}$ (MOOS-17-B) long sediment core were retrieved using a free-fall UWITEC gravity corer from a water depth of $18.7 \mathrm{~m}$ (Fig. S1). Afterwards, the cores were immeditaly stored vertically in the dark at $4{ }^{\circ} \mathrm{C}$. Before analysis, the sediment cores were split lengthwise, and sectioned at different intervals using stainless steel 
slicers and transferred to airtight containers. Core MOOS-17-B was used exclusively for dating and was sampled continously at $2 \mathrm{~cm}$ resolution. Core MOOS-17-D was used for quantification of PPP and geochemical analysis and was sampled continously at $2.6 \mathrm{~cm}$ resolution to cover approximately 3 year intervals. After the wet-sediment weight was gravimetrically determined, the samples were lyophilized (Alpha 1-2 LD, Christ GmbH, Germany).

\section{Dating and geochemical analysis}

The sediment chronology was established with ${ }^{226} \mathrm{Ra},{ }^{210} \mathrm{~Pb}$ and ${ }^{137} \mathrm{Cs}$ radionuclide dating ${ }^{12}$ on the sediment core MOOS-17-B. The isotope activity profiles were measured with gamma spectrometry at the University of Bern. Details about the equipment, background and sample treatment are provided in Tu et al., 2020. ${ }^{13}$ Unsupported ${ }^{210} \mathrm{~Pb}$ activities were calculated by subtraction of background activity from the total activity $\left({ }^{210} \mathrm{~Pb}_{\text {unsup. }}={ }^{210} \mathrm{~Pb}_{\text {tot }}-{ }^{226} \mathrm{Ra}\right) \cdot{ }^{14}$ Different age-depth models were tested (CIC, SIT, CRS) $)^{14,} 15$ with and without missing inventory (MI) corrections ${ }^{16}$ to estimate the effects of the age-depth model selection on the results. ${ }^{17}$ Detailed description is provided in Supplementary Information (SI). Additionally, the age-depth models were validated with the ${ }^{137} \mathrm{Cs}$ activity profile, whose peaks were used as independent chrono markers (Fig. S2). The 'CRS-1954 noMI'-model (constrained to the onset of ${ }^{137} \mathrm{Cs}$ at $1954 \mathrm{CE}$, Fig. S2) performed best regarding the independent ${ }^{137} \mathrm{Cs}$ chrono markers at $1963 \mathrm{CE}$ (nuclear weapon fallout peak) and $1986 \mathrm{CE}$ (Chernobyl fallout peak). ${ }^{14}, 18$ Sedimentary Mass Accumulation Rates (MAR; g/ $\left.\left(\mathrm{cm}^{2} \cdot \mathrm{yr}\right)\right)$ were calculated by multiplying the sedimentation rates (obtained from the CRS age-depth model) by the dry bulk density ( $(\mathrm{cm} / \mathrm{yr})$ $\left.*\left(\mathrm{~g} / \mathrm{cm}^{3}\right)\right)$ and were used for substance-flux calculations. The age-depth model, as well as the MAR, were projected from sediment core MOOS-17-B to sediment core MOOS-17-D following stratigraphic correlation of marker layers (Fig. S3). Additional information about the age-depth modeling can be found in SI.

Total carbon (TC), nitrogen $(\mathrm{N})$ and sulfur (S) were measured using an elemental analyzer (Vario EI Cube CNS). Total organic carbon (TOC) was calculated by TOC=TC-TIC where TIC is the total inorganic carbon and was calculated by loss on ignition (LOI, Heiri et al. ${ }^{19}$ ). Values of TC, N, S, LOI, TIC and C/N ratios are provided in Table S1.

Semi-quantitative elemental composition was determined using a $\mu \mathrm{XRF}$ core scanner $($ Avaatech XRF) 20 equipped with a rhodium tube. Two scans were conducted at $0.5 \mathrm{~mm}$ resolution - one with $10 \mathrm{kV}$ and $10 \mathrm{~s}$ exposure, and one with $30 \mathrm{kV}$ and $40 \mathrm{~s}$, to increase the elemental sensitivity. 
126

127

128

129

130

131

132

133

134

135

136

137

138

139

140

141

142

143

144

145

146

147

148

149

150

151

152

153

154

155

156

157

158

\section{Hyperspectral Imaging}

Hyperspectral measurements of green pigments (defined here as chlorophyll $a$ and $b$, and their degradation products) were done using a Specim linescan camera (PFD-CL-65-V10E) following a modified method described in Butz et al., ${ }^{21}$ (SI). Hyperspectral data were processed using ENVI 5.4 (Exelisvis ENVI, Boulder, Colorado) and the absorption trough associated with green pigments was quantified using a Relative Absorption Band Depth index (RABD) 22 in a technique similar to Schneider et al. ${ }^{23}$ The $\mathrm{RABD}_{655-685 \max }$ index is reported here as the relative abundance of green pigments and has been linearly correlated with concentrations of chlorophyll $a$ and its derivatives in Lake Moossee and other lacustrine sediments, indicative of lacustrine productivity. ${ }^{24,25}$ Additional details on the hyperspectral measurements are provided in SI.

\section{Clean-up and Enrichment of Sediment Extracts}

Sediments were extracted by pressurized liquid extraction (PLE) applying two extraction methods used previously for the extraction of pesticides in soils. ${ }^{26}$ In brief, around $4 \mathrm{~g}$ of homogenized lyophilized sample material combined with $\sim 1 \mathrm{~g}$ of diatomaceous earth (Biotage, Sweden) were extracted first with ethyl acetate and acetone at a ratio of $70: 30(\mathrm{v} / \mathrm{v})$ at $80^{\circ} \mathrm{C}$ and at 130 bar using an ASE 200 (Dionex) to extract neutral compounds. In a second ASE run the same samples were again extracted with $1 \%$ phosphoric acid and acetone in a ratio 70:30 (v/v) at $120^{\circ} \mathrm{C}$ for the extraction of acidic compounds. The extracts were combined and spiked with a mixture of 19 internal standards (absolute amount of $125 \mathrm{ng}$ of each compound) and evaporated to $500 \mu \mathrm{L}$ using a TurboVap evaporator (Biotage, Sweden) using nitrogen ( 8 psi) and at $40^{\circ} \mathrm{C}$. The evaporated extracts were mixed with $4.5 \mathrm{~mL}$ of ultra-pure water (MilliQ, Millipore) and $5 \mathrm{~mL}$ of acetonitrile. The sediment matrix was removed using QuEChERS with $\mathrm{C}_{18}$ as a dispersive solid phase extraction (250 mg Endcapped $\mathrm{C}_{18}$, BGB Analytik).

\section{Liquid Chromatography Tandem Mass Spectrometric (LC-MS/MS) Detection}

Compound separation was performed at $35^{\circ} \mathrm{C}$ on a $3.0 \times 2.0 \mathrm{~mm}$ X $3.5 \mu \mathrm{m}$ particle size $\mathrm{C}_{18}$ security guard cartridge connected to a 2.1 X $50 \mathrm{~mm}$ X $3.5 \mu \mathrm{m}$ particle size XBridge $\mathrm{C}_{18}$ column using an Agilent 1260 Infinity II HPLC system (Santa Clara, CA) by injecting $10 \mu \mathrm{L}$ of extract. The mobile phase consisted of 100\% MilliQ water (A) and methanol (B) with formic acid, 4.5 $\mathrm{mM}$ ammonium formate and $0.5 \mathrm{mM}$ ammonium fluoride added to the eluents. System parameters, elution and gradient details are provided in Table S2 and S3 in SI. 
159 Detection and quantification of analytes were carried out using a 6460 Agilent Triple Quad system with positive and negative electrospray ionization (ESI, JetStream) in different runs using dynamic multiple reaction monitoring (dMRM). In total, 215 transitions were acquired to quantify 66 PPP, 5 transformation products (TP) and 19 internal standards.

163 Substance selection was based on PPP registered and sold in Switzerland that have been reported to be applied to Swiss soils or detected in sediment samples from other Swiss lakes. ${ }^{26}$,

${ }^{27}$ Internal standards used for quantification were selected by best fit to retention time, structure similarity as well as method performance. Details on the sources of reference standards, reagents, dMRMs, and specifics on parameters are provided in the SI.

\section{Accuracy and Precision}

170 First, sediment extracts of homogenized blank sediments (here older than 100 years) were 171 spiked after PLE extraction with a mix of pesticide standards (absolute amount of $200 \mathrm{ng}$ of 172 each compound) in quadruples to evaluate the clean-up (liquid-liquid extraction (LLE) 173 QuEChERS) performance. Furthermore, the whole method performance (PLE and LLE) was assessed on homogenized blank sediments $(n=4)$ spiked with the same concentration of pesticide mix and stored in closed containers at $4^{\circ} \mathrm{C}$ for 24 hours. The sediments were then immediately extracted by PLE followed by LLE clean-up. All the samples were spiked with an internal standard pesticide mix solution after extraction for quantification.

\section{Limits of Detection and Quantification}

180 Method limits of detection (LOD) and quantification (LOQ) were calculated using the signal to noise ratios $(\mathrm{S} / \mathrm{N})$. LOD values were defined as the lowest concentration in a matrix matched calibration curve with a $\mathrm{S} / \mathrm{N} \geq 3$. LOQ values were defined as the lowest point in a matrix matched calibration curve with a $\mathrm{S} / \mathrm{N}$ ratio of 10 and MS/MS fragmentation.

\section{Data Analysis of Target PPP}

186 PPP fluxes were calculated from sediment concentrations $\left(\mathrm{pg} / \mathrm{g}_{\mathrm{dw}}\right)$ multiplied by MAR (g/ $\left.187\left(\mathrm{~cm}^{2} \cdot \mathrm{yr}^{1}\right)\right)$. Identification of trends was performed using agglomerative hierarchical cluster analysis (HCA) with the linkage method of Ward. ${ }^{28}$ The distance matrix was based on the

189 Euclidean distance of the standardized concentrations (mean $=0$ and standard deviation $=1$ ).

190 The statistical analysis was executed with the open-source software $\mathrm{R}$ including the package 191 "cluster". 29, 30 PPP sales volumes used in this work were reported by the Federal Office for 192 Agriculture (FOAG-BLW) and the Federal Department of Economic Affairs, Education and 
193 Research (EAER-WBF) and cover the period from 2008 to 2018. Although, the local use of

194 PPP is documented in agricultural diaries, the data are not publicly available. Therefore, sales data used here represent all of Switzerland.

\section{Ecological Risk Assessment}

198 An ecological risk assessment (ERA) was conducted based on ecotoxicity data from freshwater 199 organisms since not enough ecotoxicity data for sediment-dwelling organisms are available. 200 Risk quotients (RQ) were calculated based on chronic environmental water quality standards 201 (AA-EQS) and measured concentrations. The AA-EQS values were derived in accordance with the Technical Guidance Document of the European Union. ${ }^{31}$ AA-EQS values were taken from the proposal for acute and chronic quality standards from the Swiss Center for Applied Ecotoxicology 32 or from Environmental Quality Criteria (EQC) values derived from different literature as detailed in SI. For transformation products, the AA-EQS values of the parent compounds were considered for the risk assessment since no EQC values were available. RQ values for sediment and predicted pore water concentrations $\left(\mathrm{C}_{\mathrm{ipw}}\right)$ were calculated by using the organic carbon sorption coefficient values $\left(\mathrm{K}_{\mathrm{oc}}\right)$, sediment concentration $\left(\mathrm{C}_{\mathrm{ised}}\right)$, and the fraction of organic carbon $\left(\mathrm{f}_{\mathrm{oc}}\right)$ of the lake as described in detail in SI. Mixture toxicity ( $\mathrm{RQQ}$ ) was evaluated using a concentration addition model by adding individual RQs for each sample as a first tier assessment irrespective of the modes/mechanisms of action of the mixture components. ${ }^{33}$ Furthermore, $\Sigma$ RQ were calculated according to PPP classes as performed by Moschet et. al., ${ }^{8}$ in order to determine which substance classes contributed the most to the total environmental risk. Details on the ERA, equations, values used, and RQ values description are reported in Table S6, S7 and S9 and in SI.

\section{Visualization of Nontarget Trend Analysis}

218 Nontarget trend analysis was used as an exploratory tool to investigate the overall 219 contamination of Lake Moossee and was performed by a high resolution mass spectrometer 220 (HR-MS) using a quadrupole Orbitrap (Q-Exactive Plus, Thermo Fisher Corp., USA) at the 221 Bernese cantonal laboratories. Full scan accurate mass spectra were acquired from 100 to 800 Da with resolving power of 140000 reference to $200 \mathrm{~m} / \mathrm{z}$ and mass accuracy of $\pm 5 \mathrm{ppm}$ using electrospray ionization (ESI) in positive and negative ionization in independent injections.

224 Details of chromatographic separation and detection have been described in details elsewhere. ${ }^{10}$ 225 Temporal trends were detected by sorting identical exact masses into time series using 226 enviMass version 4.0 using configurations as described by Chiaia-Hernández et al., 2017. ${ }^{10}$ 
Mass recalibration, global intensity correction, RT alignment and blank subtraction were included within the enviMass workflow. The profiles obtained were not grouped further to avoid loss of information. However, $\sim 20 \%$ of the total masses are expected to be isotopes and adducts from the detected profiles. ${ }^{10}$ Blank subtraction was performed automatically with homogenized blank sediment samples ( $\sim 100$ years old). Nontarget trend detection to identify compounds of anthropogenic origin was performed using Spearman rank correlation $(\rho \geq 0.5)$ and agglomerative HCA with data scaling (divided by the sum of the profile), measurement of similarity (Euclidean distance) and clustering (Ward's minimum variance) as described in previous work. ${ }^{10}$ Identification of profiles (features) was performed by an in-house suspect screening list using enviMass version 4.0 and $>200$ reference standards and includes pharmaceuticals, personal care products, industrial chemicals and pesticides. ${ }^{27,34}$

\section{Results and Discussion}

\section{Method Performance}

241 The accuracy and precision of the method are illustrated in Fig. 1. The results show average recoveries of $80 \%$ (range from $40-120 \%$ ) and method precision, indicated by relative standard deviation (RSDEV \%), of $8 \%$ (range from 2 to $24 \%$ ). Accuracy and precision of individual PPP as well as LLE recoveries are provided in Table S8. There was no correlation between recoveries and $\log \mathrm{K}_{\mathrm{ow}}$ values $\left(\mathrm{r}^{2}=0.288, \mathrm{p}=0.018\right)$ as shown in Fig. S4. LOD and LOQ values are reported in Table S8 and range from 60 to $600 \mathrm{ng} / \mathrm{kg}_{\mathrm{dw}}$ with an average of $80 \mathrm{ng} / \mathrm{kg}_{\mathrm{dw}}$ and from 60 to $1250 \mathrm{ng} / \mathrm{kg}_{\mathrm{dw}}$ with an average of $220 \mathrm{ng} / \mathrm{kg}_{\mathrm{dw}}$, respectively. Overall, the results show that a modified clean-up method originally developed for detecting pesticides in soils ${ }^{26}$ can be successfully applied to sediment samples to detect PPP covering different compound classes and polarities ( $\log \mathrm{K}_{\mathrm{ow}}-1.7$ to 5.2 , pKa 1 to 12$)$. Additionally, the method shows similar or significantly improved recoveries, RSDEV (\%) and lower LOQ values when compared to other sediment extraction methods for PPP conducted with HR-MS/MS and triple-quadrupole (QqQ) instruments. ${ }^{34-38}$

\section{Lake sediment properties and context}

Sediments consist of brown organic-rich silt with light-colored endogenic calcite laminations. The ${ }^{210} \mathrm{~Pb}$ chronology (Fig. 2) indicates relatively constant sedimentation rates during the past 100 years. MAR vary from 0.09 to $0.23 \mathrm{~g} /\left(\mathrm{cm}^{2} \cdot \mathrm{yr}^{1}\right)$. The abundance of green pigments (chlorophylls and diagenetic products) shows an increasing eutrophication trend beginning in 1925, with the greatest algal production occurring from 1960-1980. This period is associated 
261

262

263

264

265

266

267

268

269

270

271

272

273

274

275

276

277

278

279

280

281

282

283

284

285

286

287

288

289

290

291

292

293 294 show the highest concentrations between the 1980s and the 1990s, followed by a systematic

with better seasonal lamination preservation in the biogenic varves (indicative of anoxic bottom waters), higher flux of TIC (increased calcite precipitation), and slightly reduced TOC:TN ratios (indicative of a shift toward higher proportion of aquatic organic matter). We attribute this period of enhanced lacustrine productivity to increased concentrations of $\mathrm{P}$, which were observed in many lakes across Switzerland. ${ }^{39}$ The introduction of a $\mathrm{P}$ trapping wastewater treatment plant (WWTP) in 1963, regulatory measures in the agricultural sector, and the ban of phosphates in detergents in 1986 led to the reduction of external P loadings to the lake, and a subsequent decline in aquatic production can be observed in decreased green pigment values after 1980. The sediments above $20 \mathrm{~cm}$ (approximately 1981 and following years) appear to be increasingly bioturbated and there is a shift towards less TIC and Ca. These changes are related to reduced productivity, which led to reduced hypolimnetic oxygen consumption and decreased precipitation of calcite. Overall, there is little long-term trend in Ti counts, indicating generally consistently low input of detrital material from the catchment and low surface processes (soil erosion) in the catchment. Sulfur (S) is consistently present throughout the record, indicating that sediments remained anoxic during the study period.$^{40}$ The greater variability of the elemental composition in the lower part of the sediment (prior to 1986) is related to better preservation of seasonal laminae and the absence of bioturbation. Bioturbation in the upper part smooths out seasonal variability of the sediment composition.

\section{Plant Protection Products in Sediments}

Sediment analysis of Lake Moossee reveals the presence of 34 PPP, which corresponds to $\sim 50 \%$ of the investigated compounds (Fig. S5). PPP start appearing in the lake for the first time in the early 1960s with $74 \%$ of the PPP showing highest concentrations between the 1980s and late 1990 s and with $26 \%$ still on the rise. Herbicides and fungicides were equally found in sediments with 16 compounds in each class and only two insecticides detected. Since 2005, fungicides are the dominant class of PPP suggesting additional input sources to the lake or a change of land use. Based on PPP concentrations (normalized to TOC) and fluxes patterns over the last ca. 90 years, detected PPP can be divided in five clusters as illustrated in Fig. 3 and S6.

\section{Cluster Analysis of PPP}

\section{Cluster 1}

92 Five herbicides (atrazine, dinoseb, isoproturon, linuron, nanopramide), one fungicide 93 (metalaxyl-M), and one TP (terbuthylazine-2-hydroxy) fall into this cluster. These seven PPP 
increased between 2005 to 2010 and a constant decrease towards the sediment surface (2017).

296 These decreasing trends reflect the ban of some herbicides like dinoseb in 2002 and atrazine in 2012 in Switzerland or the drop in sales of these compounds. For example, sale volumes obtained for isoproturon and linuron in the last twelve years have dropped between $80 \%$ and 100\%, respectively (Fig. S7).

300 Despite the ban of dinoseb and atrazine, they can still be detected in more recent sediments, revealing their persistence in the environment. This is in line with latest studies that detected atrazine and its TP in more than $80 \%$ of Swiss groundwaters. ${ }^{41}$ PPP can reach groundwater and lake systems by seepage from agricultural soils. ${ }^{41,42}$ During this process, PPP may undergo natural attenuation processes such as sorption or degradation processes. ${ }^{41,42}$ Therefore, while the surface water contamination usually relates to PPP application during the farming season, ${ }^{43}$ the contamination of groundwater and sediments with PPP demonstrate the transport and persistence of these substances across different compartments of the environment. In 2012, isoproturon, linuron and metalaxyl-M were reported in river catchments distributed over the Swiss plateau, however, additional PPP reported here were not detected.

Cluster 2

312 This cluster includes the herbicides chloridazon, diuron and simazine, which all show 313 increasing fluxes in the late 1960s and a sharp decrease towards the present (2017). Introduction 314 of these herbicides to the lake (before 1970) and first peak fluxes are visible earlier than the 315 other detected PPP, which is consistent with the marketing of chloridazon and simazine in the 3161960 s and diuron in the 1950s. ${ }^{44}$ Herbicides in this cluster, along with other PPP in cluster 1 317 (e.g. atrazine, isoproturon, nanopramide and a TP of terbuthylazine), are some of the oldest PPP 318 reported. ${ }^{44}$ The ban of simazine in 2012 and the reduced sale-volumes of chloridazon (e.g., $80 \%$ since 2008) and diuron can be observed with PPP concentrations close to zero ( $<$ LOD) in recent sediment layers (Fig. 3 and S7). The temporal trend of reconstructed fluxes of these three herbicides in Lake Moossee are in agreement with their detection in different environmental compartments such as groundwater, surface waters, soil and, to a lesser extent, in sediment samples. ${ }^{8,26,41,44}$

Cluster 3

326 Six PPP are included in this cluster with highest fluxes around 2005 to 2010, followed by a constant decrease towards the sediment surface, with some compounds reaching concentrations

328 below their LOD (e.g. fungicide cyprodinil). Peak fluxes from PPP included in this cluster lag 
329 by 10-20 years compared to the fluxes of compounds contained in clusters 1 and 2 . In cluster 3303 , orbencarb is the only herbicide detected and fungicides are the dominant pesticide class as 331 shown by high abundances of carbendazim, fenpropimorph, flusilazole, and prochloraz. The 332 findings are surprising since herbicides are usually reported as the most detected pesticide class 333 in surface waters close to agricultural catchments. ${ }^{8}{ }^{45}$ In 2015, fungicides were one of the most 334 widely use PPP in Europe (42\%), followed by herbicides (34\%). ${ }^{46}$ Therefore, our findings could 335 suggest a higher availability and thus a higher use of fungicides in the last years. Furthermore, 336 the availability of analytical standards to detected fungicides has significantly expanded (last 10 years) helping to identify fungicides not studied in the past due to the lack of reference materials. The increasing number of fungicides detected might be also attributed not only to agriculture fields but perhaps to additional sources of contamination. In 2003, a golf course was built at the east side of the lake (Fig. S1). Thus, the increased of fungicides could be linked to the golf course and might explain the systematic increased of PPP in cluster 1 around the same time. Fungicides (e.g., carbendazim and prochloraz) and insecticides are frequently applied to golf course turfs to control surface activities of earthworms and management of fungal diseases. ${ }^{47,48}$ So far, water quality monitoring has focused on agriculture chemicals ${ }^{8}$, however, pesticides applied to turfgrass systems like golf courses, home lawns and parks have rarely been included in monitoring campaigns. ${ }^{49}$ To pinpoint the specific reason for the increase of fungicides in Lake Moossee further studies are needed (e.g., spatial analysis). The decrease trends observed in this cluster are consistent with the bans (e.g., orbencarb since 2011 and carbendazim in 2018) and sales reduction of these fungicides (Fig. S7) with the exception of fenpropimorph, whose sales have been increasing in the last 10 years but its concentrations have constantly decreased since the late 1990s. Moreover, carbendazim shows a surging concentration towards 1980 following by a decreased around the 1990s resembling a similar trend as diuron (cluster 2). The decrease in concentration might be linked to the implementation of the Water Protection Act (WPA, 1991) in Switzerland, however, this pattern is not reflected in any other PPP and additional trend interpretation based on PPP application, sales or soil management is not possible since the data is not publicly available. From this cluster, carbendazim, cyprodinil, flusilazole, and fenpropimorph have been reported in surface and groundwaters in Switzerland. ${ }^{8,41}$

361 In this cluster, PPP show a delay in peak concentrations of $>15$ years compared to compounds 362 in cluster 1 . Cluster 4 includes ten PPP with peak concentrations in the last 12 years and 
decreasing trends over the recent years, except for the herbicides diflufenican, metolachlor and pendimethanil and the insecticide fipronil (Fig. 3). Additional PPP in this cluster are the fungicides cyproconazole, propiconazole, tebuconazole, fenpropidin and fludioxonil, and the herbicide ioxinyl. In Switzerland, the application of ioxynil has been prohibited since 2018. However, decreasing fluxes of ioxynil can be observed already before the ban (from 2005 onwards; Fig. 3). The reconstructed PPP fluxes in this cluster are consistent with their sales patterns except for the insecticide fipronil. Fipronil has been banned in Switzerland since 2011 due to its high toxicity to bees. ${ }^{50}$ Thus, its detection in recent sediment layers could be attributed to a delay from fipronil last application or for other additional sources. Fipronil was also used for seed treatment in low amounts and as biocide. However, data on these application are not available. ${ }^{51}$ Fipronil has been detected in surface waters ${ }^{8}$ and its TPs have been recently reported to occur in sediment samples and in groundwater with direct influences of agriculture, which is in agreement with our results. ${ }^{27,}{ }^{41}$ Similar to our findings, a recent study reported a wide distribution of antifungal azoles chemicals (e.g., cyproconazole, propiconazole, tebuconazole) in aquatic and terrestrial ecosystems. ${ }^{52}$ Besides fipronil, only the herbicide metolachlor and the fungicide fenpropidin have been reported in groundwater and surface waters, respectively. ${ }^{8,41}$

\section{Cluster 5}

Eight PPP are included in this cluster (the fungicides azoxystrobin, difenoconazole, epoxiconazole, fluazinam; the herbicides flufenacet, fluopicolide, prosulfocarb; the insecticide chlorpyrifos) with constantly increasing fluxes since the 1990s (Fig. 3). PPP in this cluster show a delay in peak concentrations of $>19$ years against compounds in clusters 1 . In this cluster, sales volumes do not always compare with the trends observed. The increasing trends of PPP in this cluster might suggest a preference of the farmers for these substances in recent years, a change in land use and/or additional contribution from other sources (e.g., golf course since 2003). In 2012, cereals were reported as the most important crops in the lake catchment, ${ }^{8}$ which is in agreement with the use of fungicides detected and their usual application to control diseases in cereals. The PPP detected are also applied to other crops such as root crops, legumes, and fruit trees, in addition to cereals, which might indicate a shift in land use. The increase in fungicides could be also attributed to the use of fungicides in the golf course as in the case of carbendazim and prochloraz in cluster 3, cyproconazole, propiconazole, tebuconazole and fludioxonil in cluster 4 , and azoxystrobin in cluster 5 , which are fungicides usually applied to 
396 turf grasses. ${ }^{48,}{ }^{49}$ However, additional studies are needed to identify the main reason for the 397 increase of fungicides in Lake Moossee in the last $\sim 12$ years.

398 With the exception of fluopicolide all the PPP in this cluster have been reported to occur in 399 surface waters but not yet in groundwater. ${ }^{8}$

400

401

402

403

404

405

406

407

408

409

410

411

412

413

414

415

416

417

418

419

420

421

422

423

424

425

426

427

428

429

\section{Risk Assessment}

Since 2010, concentrations of individual sedimentary PPP range from $<1$ to $300 \mu \mathrm{g} / \mathrm{kg}_{\mathrm{oc}}$ with the fungicides difeconazole and epoxiconazole, the herbicides prosulfcarb, diflufenican, and phedimethanil having the highest concentrations (Fig. S5). Single substance risk assessment, which is the least conservative risk assessment scenario, resulted in good sediment quality for most of the detected PPP with RQ values $<1$. However, the herbicides diflufenican and dinoseb show values of $1 \leq R Q \geq 2$ (moderate) and the organophosphate insecticide chlorpyrifos display values of $R Q \geq 4$ (insufficient). RQ values $>1$ indicate impaired sediments that may pose a risk to aquatic organisms. Studies carried out at sites NAWA SPEZ in Switzerland in 2017 demonstrate that chlorpyrifos showed the highest concentrations among the target PPP in stream sediment samples, which is consistent with our results. ${ }^{53}$ Chlorpyrifos, banned in Switzerland as 2020, is known for its high toxicity to fish, aquatic invertebrates, bees and bumblebees. ${ }^{54}$

PPP do not occur as single substances in the environment; thus, organisms are usually exposed to mixtures of substances. In this work, mixture toxicity was assessed as the worst-case scenario ( $\Sigma \mathrm{RQ}$ ). Following this approach, the results show that $\Sigma \mathrm{RQ}$ values started from $\Sigma \mathrm{RQ} \leq 1$ (good) in the 1970s to $2 \geq \Sigma R Q \leq 8$ (insufficient; Fig. 3) starting in the 1980s. The high toxicity risk quotients are mainly attributed to herbicides and insecticides with calculated $\Sigma \mathrm{RQ} \geq 3.5$ (insufficient), accounting each for more than 40\%. Even though, in this work, only two insecticides were detected, the $\Sigma$ RQ values are mainly attributed to chlorpyrifos. The high EQS obtained for chlorpyrifos can be ascribed mainly to a combination of higher concentrations found in the sediments ( $\geq 28 \mu \mathrm{g} / \mathrm{kg}_{\mathrm{oc}}$ ) and high predicted $\mathrm{K}_{\mathrm{oc}}$ values used when compared to other detected PPP. Subsequently, fungicides contribute only $10 \%$ to the toxicity risk even though they were equally abundant as herbicides. Lake Moossee is used as a recreation area with swimming facilities in the summer. The risk assessment performed in this work does not evaluate the risk posed to humans. Therefore, our findings call for studies to evaluate the exposure of people who frequently use these recreational areas.

Porewater is a major route of exposure of many benthic organisms to contaminants since contaminants in this matrix are more bioavailable. ${ }^{55}$ Thus, pore water concentrations were 
predicted based on sediment concentrations between 2014-2017 (top layer). Pore water concentrations range from non-detectable to $130 \mathrm{ng} / \mathrm{L}$ with the $\mathrm{TP}$ of the herbicide terbuthylazine, the fungicide carbendazim, and the herbicides prosulfocarb, atrazine and dinoseb as the top five PPP in decreasing order. Sedimentary concentrations of up to $5 \mathrm{ng} / \mathrm{kg}_{\mathrm{oc}}$ were measured for the banned compounds atrazine and dinoseb (banned in 2012 and 2002, respectively) in the most recent sediments. While their $\sum R Q$ values are lower than 2 (moderate), atrazine and dinoseb detection emphasize their persistence and their lagged contamination of the lake.

438 Previous studies conducted in Lake Moossee, report high stability of pesticides and TPs at different water depths under anaerobic conditions with TP strongly outweighing parent compounds. ${ }^{56}$ In our study, only a few TP were included as a proof of concept. However, the detection of the terbuthylazine TP in sediments reveals the persistence and mobility of TP and the need to include them in future studies. Calculated RQ values, pore water predicted concentrations and physico-chemical properties are reported in Appendix A and in SI Table S8 and S9.

\section{Nontarget Trend Analysis of Lake Moossee Sediments}

447 Nontarget trend analysis was used in this work to capture additional anthropogenic organic contaminants not covered in the PPP target analysis. Profiles captured by sorting identical exact masses into time series, reveal $>2,000$ profiles of unknown compounds in positive ionization and $>900$ in negative ionization. The profiles were grouped by HCA and divided in six clusters as illustrated in Fig. 4. The nontarget clusters display similar trends obtained by target analysis as demonstrated for cluster $\mathrm{A}$ and $\mathrm{E}$ for selected targeted substances and unknown compounds (profiles shown in grey, Fig. 4). Only cluster A and B ( $\leq 28 \%$ of the unknown compounds)

454 show increasing concentrations until today as revealed by the higher color intensities in the heat map. Examples of targeted PPP in cluster B encompass the fungicides prosulfcarb and difeconzole which show constant increasing concentration since the 1990s (cluster 5 in Fig 3 and S8).

458 Input of many more substances than identified with the target analysis start appearing in the 1970s, followed by a decrease of contaminants at the beginning of the 1990s and a constant increase of different types of contaminants $(\leq 28 \%)$ since the year 2000 . The observations can be related to the increase in agriculture and PPP production as well as the construction of a highway in the catchment in the 1970s. ${ }^{3}$ Between the 1960s and late 1980s implementation of environmental policies and water protection initiatives helped to stop some organic 
464

465

466

467

468

469

470

471

472

473

474

475

476

477

478

479

480

481

482

483

484

485

486

487

488

489

490

491

492

493

494

495

496

497

contaminants reaching the lake, as seen in Fig. 4 (dotted line) with the disappearance of some profiles. However, the removal of contaminants in Lake Moossee after the 1980s was not as significant as observed for other lakes (e.g., Lakes Greifensee and Lugano) in Switzerland, ${ }^{10}$ indicating that contaminants originated from WWTP effluents have little or no substantial presence in the lake. The constant increase of additional contaminants since the year 2000 as seen in Fig. 4 (Cluster A, dash-point line,) is consistent with the construction of a golf course built at the east side of the lake in 2003. However, further studies are needed to find the specific reason of this increase. Due to the coverage of the analytical method employed (e.g., log Kow -1.7 to 5.2 , pKa 1 to 12 , nonvolatile), the nontarget visualization and the description of the catchment, the unknown compounds are most likely compounds (including TP) with similar physicochemical characteristic as the target PPP entering the lake by diffuse input sources (e.g., turfgrass, agriculture, livestock systems). Additional sources of contamination are compounds (e.g., biocides) released by urban environments, such as compounds leaching from the adjacent highway $(\geq 33 \mathrm{~m})$ and material protection agents on facades and roofs. As a proof of concept and to support our assumptions, suspect screening was performed to capture additional organic contaminants not covered by the target analysis. The suspect screening resulted in the confirmation of four additional compounds which include i) the herbicide chlorotoluron (cluster A, Fig. 4) used for controlling grass weeds in cereals, cotton and fruit production, ${ }^{57}$ ii) propazine-2-hydroxy a TP of the herbicides prometon, prometryn, and propazine (cluster E, fig 4), and iii) the biocides irgarol and 2-octyl-2H-isothiazol-3-one (OIT). The identified PPP and biocides support our assumptions. The nontarget trend analysis highpoints that the target analysis of $>60$ prioritize PPP falls too short for a comprehensive assessment of organic pollutants and risk assessment. In this work, only $\sim 2 \%$ of nontarget time series with increasing concentrations (intensities) until today are known (600 profiles - cluster A and B in Fig.4 and S8). Thus, further efforts need to be put on the identification of major sources of contamination to the lake as well as on the identification of unknown substances using much larger databases (e.g NORMAN SusDat $)^{58}$ which could allow the tentative identification of many more compounds.

\section{Insights and Future Research}

The applied analytical method helped to identify more polar and mobile compounds than previously reported in PPP sediment analysis. Our findings confirm that PPP embedded in sediments are often quite stable, especially under anaerobic conditions. By adopting paleolimnological methods (e.g., chronology, hyperspectral measurements of sedimentary 
green pigments and XRF) and applying a multiproxy-workflow, our work reveals that PPP fluxes are not related to sedimentological processes such as soil erosion (Ti counts, XRF) or lake biogeochemistry like precipitation of calcite or lake productivity (green pigments, HSI). While there is some evidence for less anoxic conditions after the 1980s with poorer varve preservation, there is no strong effect from this change in the PPP data. As a result, postdepositional processes or variations in sediment binding do not majorly influence PPP fluxes over time and PPP behavior can be related mainly to sales (used as a proxy for PPP application) or bans.

Sediment records indicate PPP start appearing in the lake for the first time in the early 1960s with herbicides and fungicides being equally found in sediments. The detection in recent sediment layers of PPP that are not yet reported in other environmental compartments (e.g. groundwater) can help identify possible persistent compounds in the future. The nontarget analysis reveal significant inputs of contaminants to the lake starting in the 1970s, followed by a decrease of contaminants at the beginning of the 1990s and a constant increase of different type of contaminants since the year 2000. Based on suspect screening additional PPP (chlorotoluron and propazine-2-hydroxy) and two biocides (irgarol and OIT) were confirmed.

514 The risk assessment on targeted PPP indicates that since the 1980s the sediment quality is insufficient. RQ values displayed maximum levels in the most recent sediments, despite bans of specific PPP and environmental regulations. Until today, there are no legal regulations in place concerning sedimentary PPP concentrations. Neither exists any harmonized approach to assess sedimentary quality regarding PPP. Thus, due to the absence of AA-EQS for sediments, the risk assessment conducted in this work for detected PPP is only a rough estimation but overall the true risk is much higher since $>2000$ unidentified compounds were not included in the assessment.

Lake systems like Lake Moossee are abundant in the Swiss plateau and Europe and are often used as freshwater supplies. Therefore, our findings are likely representative of many agriculturally influenced lakes in Europe. The present study calls for further studies to investigate the mechanisms of organic contaminants in sediments, particularly, how PPP and other organic contaminants are reaching the lake and the lake sediments, and if these compounds can be remobilized. Equally, there is an urgent need to establish AA-EQS for sediments and to understand how sedimentary PPP affect lacustrine ecosystems.

\section{Supporting Information}


531 Additional information on site description, chronology, analytical methods, method

532 performance, fluxes, concentrations and temporal patterns, and risk assessment of PPP.

\section{Appendix A}

534 Fluxes, concentrations, risk quotients and pore water concentrations. Raw files of HR-MS

535 data are available on request.

\section{Acknowledgements}

538 The authors thank Daniela Fischer, Patrick Neuhaus and Linus Rösler for their help in the 539 laboratory, Stamatina Makri and Luyao Tu for their help in the field, Martin P. Frey (ZHAW) 540 for his advice in statistics and R, Matthias Ruff (Bernese cantonal laboratories -BVE-WAW541 GBL) for the LC-HRMS analysis, Martin Loos (loos computing-envibee) for envimass free 542 license, Pablo Lara-Martin (University of Cádiz), and Carmen Casado-Martinez (ecotoxcenter) 543 for their thorough discussions. Funding by the University of Bern through the Interfaculty 544 Research Cooperation One Health and SNSF grant 200021-172586 are gratefully 545 acknowledged.

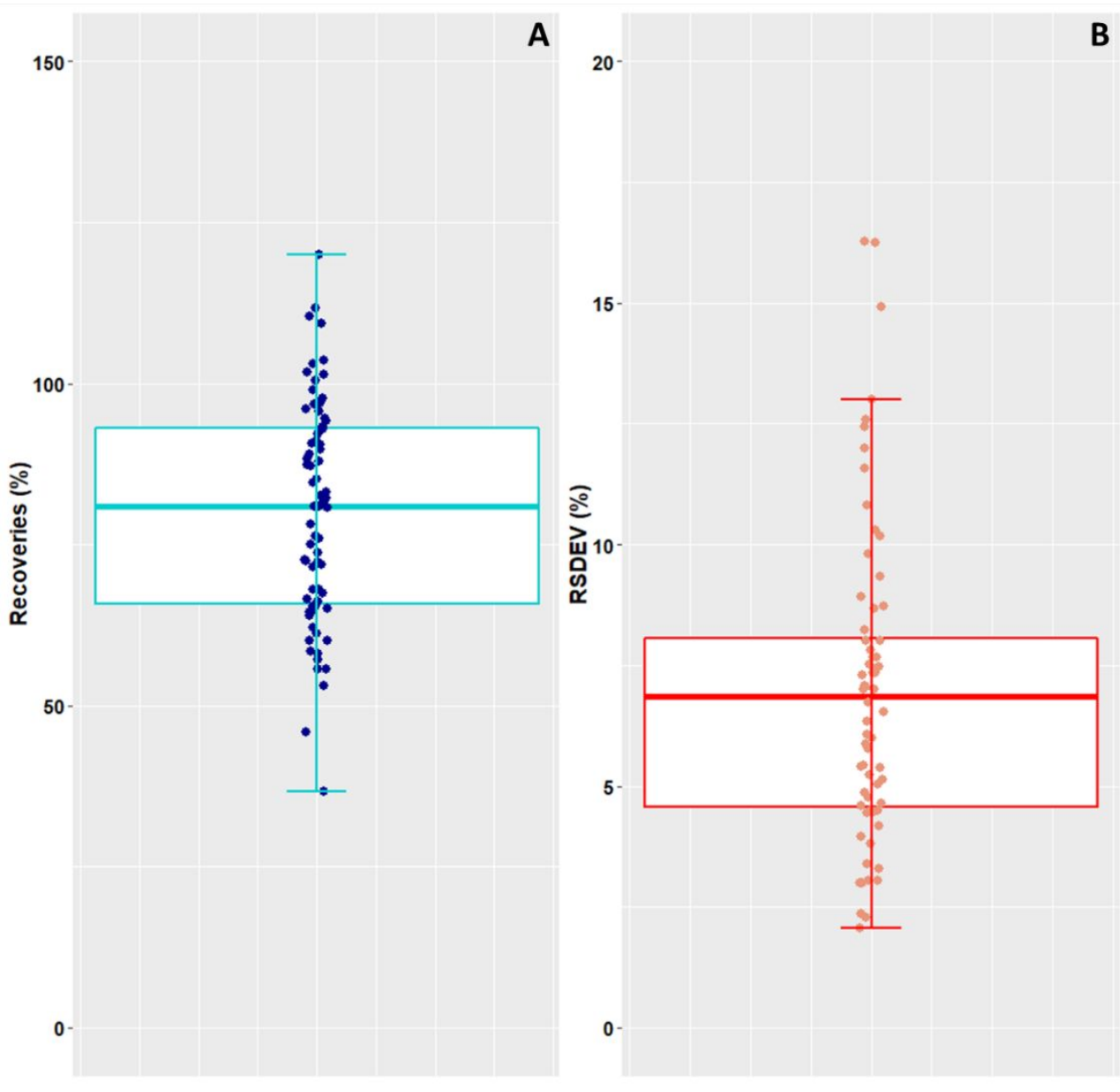


Fig. 1. Method accuracy and precision of $66 \mathrm{PPP}$ and five transformation products with box plots showing recoveries (\%, A panel in blue) and relative standard deviation (RSDEV \%, B panel in red). Color points represent individual measurements. Accuracy and precision of individual PPP is provided in Table S8.

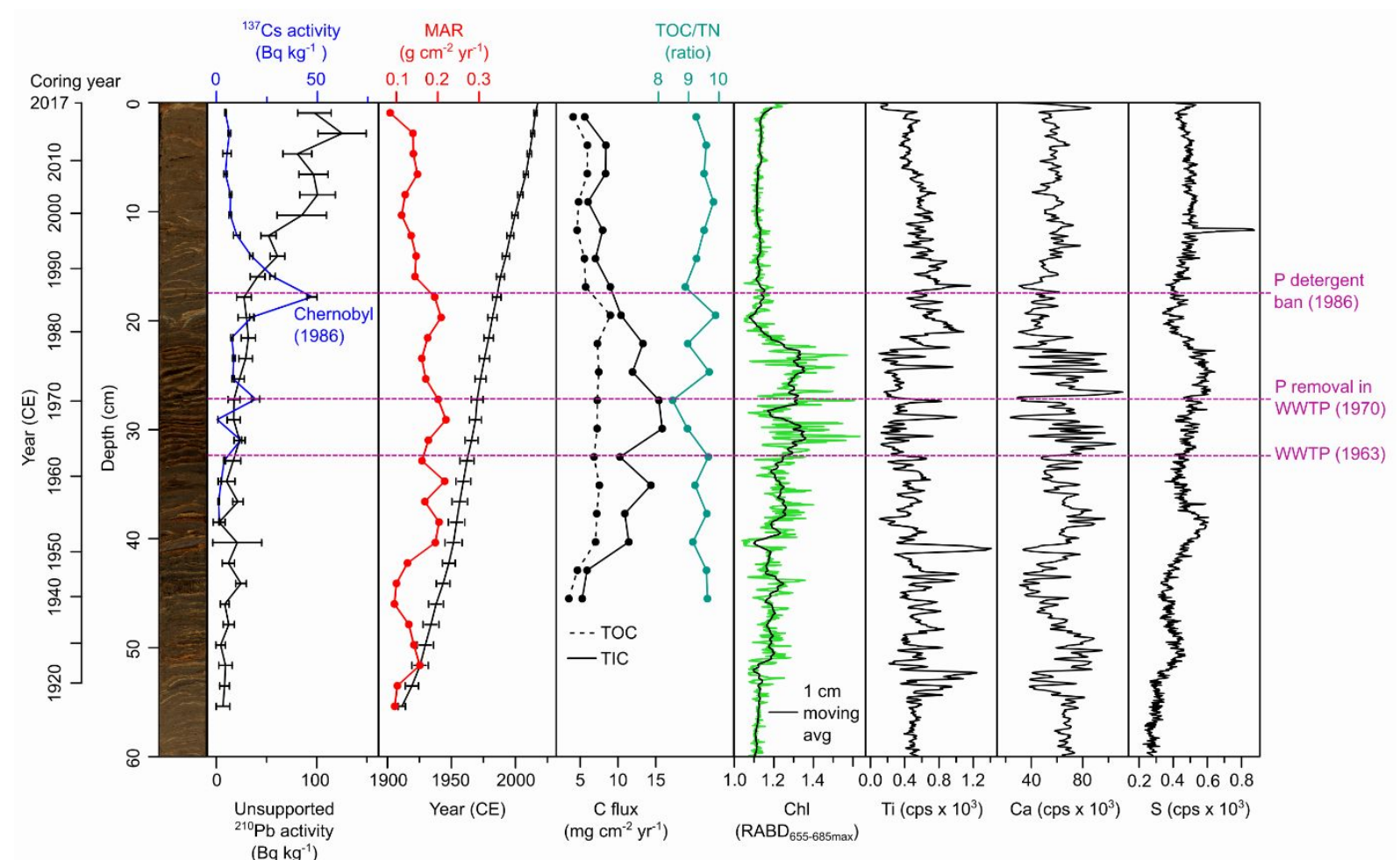

Fig. 2. Illustrates, from left to right, a sediment core picture of Lake Moossee (MOOS-17-D), Cesium $\left({ }^{137} \mathrm{Cs}\right)$ and lead $\left({ }^{210} \mathrm{~Pb}_{\text {unsupported }}\right)$ activity, mass accumulation rates (MAR), total organic carbon (TOC), total inorganic carbon (TIC), ratios of TOC to total nitrogen (TN), abundance of green pigments (Chl), titanium (Ti), calcium (Ca), and sulfur (S). Pink horizontal lines represent the installation of the first wastewater treatment plant (WWTP) in the catchment in 1963, phosphorus removal in WWTP in 1970, and the ban of phosphorus in detergents in 1986, respectively. 

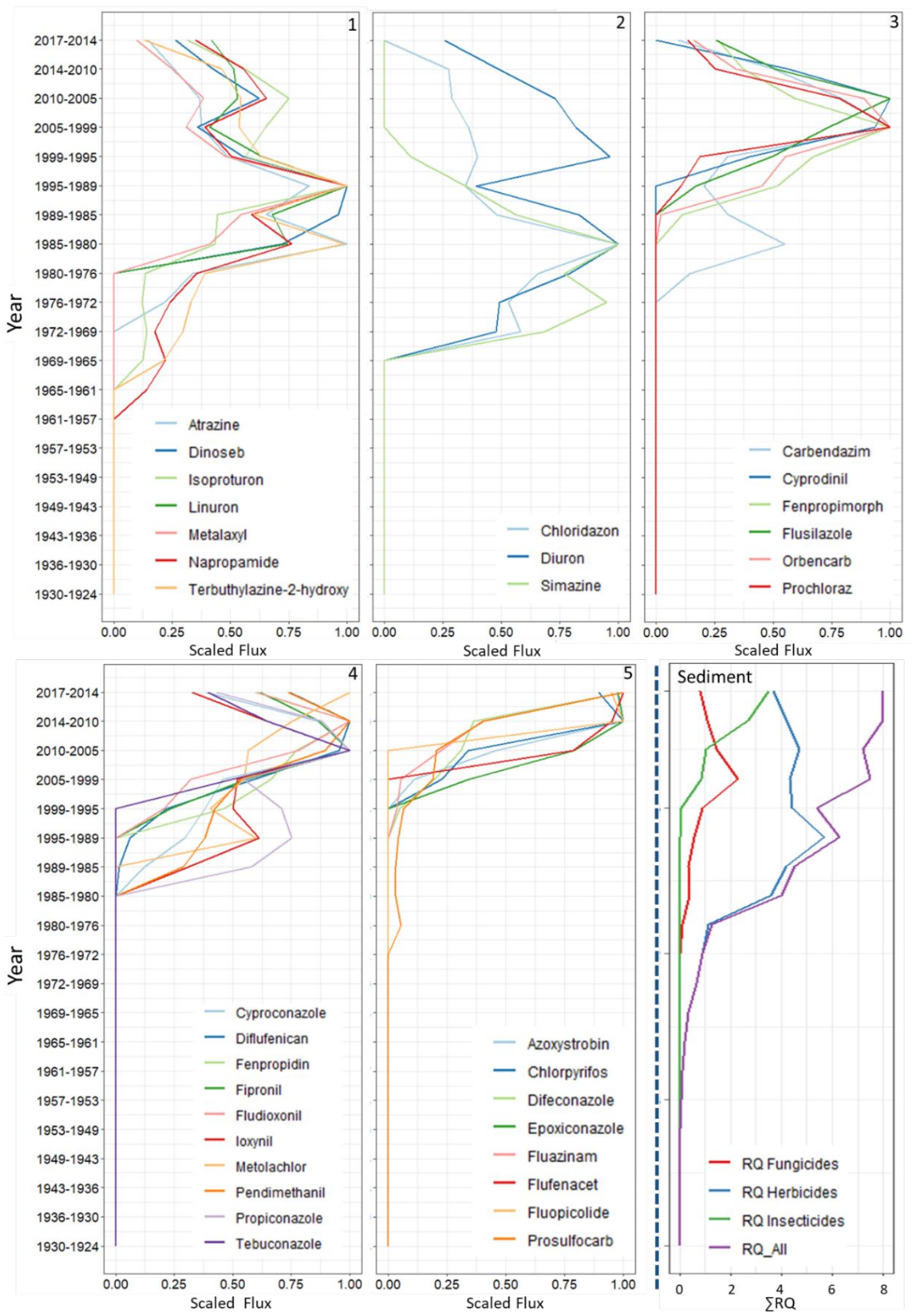

Fig. 3. Vertical concentration profiles sorted by hierarchical cluster analysis of 34 PPP (panel

563 1-5) detected in sediments of Lake Moossee showing five different clusters over time with

564 scaled fluxes. The panel on the lower right shows mixed toxicity values ( $\mathrm{RQ})$ for sediments

565 with PPP total contribution (RQ_ALL) and their contribution for each PPP class (fungicides,

566 herbicides, and insecticides). 

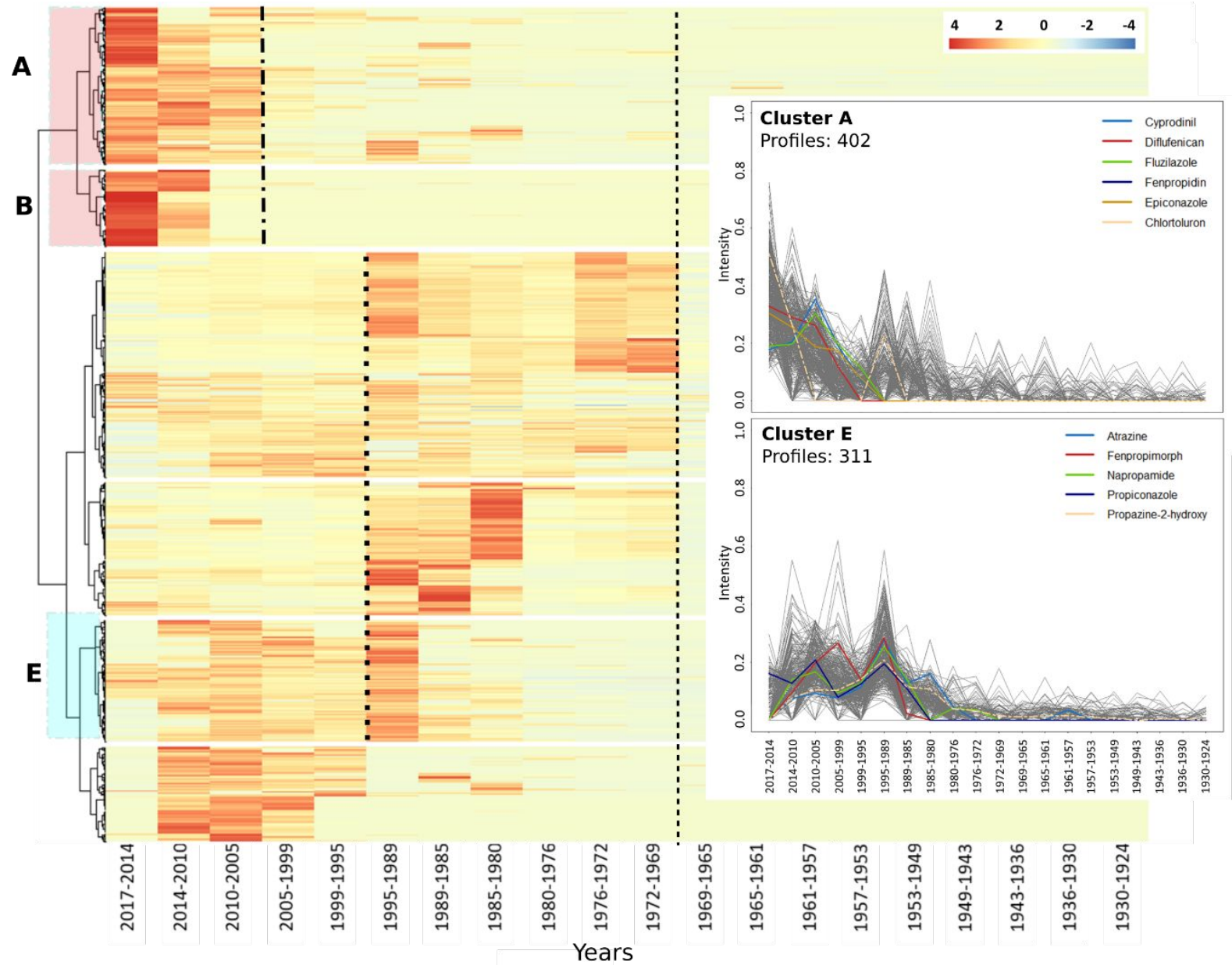

568 Fig. 4. Heat map of unknown standardized substances grouped by hierarchical cluster analysis

569 (HCA) detected in sediments of Lake Moossee in positive ionization $(n=2,073)$. Significant

570 inputs of contaminants are visible at the beginning of the 1970s (dash black line).

571 Environmental policies and water protection initiatives between the 1960s and late 1980s had

572 an effect in the lake shown by the decreased of signals of unknown profiles (point line). Cluster

573 A and B highlight new features appearing since 2005 and still increasing until today (dash-point

574 line). Plots of cluster A and E are plotted with the corresponding captured profiles (grey), detected target compounds and new detected compounds (doted white lines) in same cluster. 


\section{References}

579 1. Aktar, M. W.; Sengupta, D.; Chowdhury, A., Impact of pesticides use in agriculture: their benefits and hazards. Interdiscip Toxicol 2009, 2, (1), 1-12.

581 as a focus. In International Academy of Ecology and Environmental Sciences 2011; Vol. 12. 3. Mateo-Sagasta, J.; Marjani Zadeh, S. T., H., More people, more food, worse water? A global review of water pollution from agriculture.

http://www.fao.org/3/ca0146en/CA0146EN.pdf. Accessed 01.03.2020. In The Food and Agriculture Organization of the United Nations (FAO): 2018.

4. Morris, B. L.; Lawrence, A. R. L.; Chilton, P. J. C.; Adams, B.; Calow, R. C.; Klinck, B. A., Groundwater and its susceptibility to degradation: a global assessment of the problem and options for management. Early Warning and Assessment Report Series, RS. 03-3. Kenya, UNEP (United Nations Environment Programme). 2003. 5. Bernhardt, E. S.; Rosi, E. J.; Gessner, M. O., Synthetic chemicals as agents of global change. Frontiers in Ecology and the Environment 2017, 15, (2), 84-90.

6. Carneiro, R. P.; Oliveira, F. A. S.; Madureira, F. D.; Silva, G.; de Souza, W. R.; Lopes, R. P., Development and method validation for determination of 128 pesticides in bananas by modified QuEChERS and UHPLC-MS/MS analysis. Food Control 2013, 33, (2), 413-423.

7. Del Prado-Lu, J. L., Insecticide Residues in Soil, Water, and Eggplant Fruits and Farmers' Health Effects Due to Exposure to Pesticides. Environmental Health and Preventive Medicine 2015, 20, (1), 53-62.

8. Moschet, C.; Wittmer, I.; Simovic, J.; Junghans, M.; Piazzoli, A.; Singer, H.; Stamm, C.; Leu, C.; Hollender, J., How a Complete Pesticide Screening Changes the Assessment of Surface Water Quality. Environmental Science \& Technology 2014, 48, (10), 5423-5432.

9. Krauss, M.; Singer, H.; Hollender, J., LC-high resolution MS in environmental analysis: from target screening to the identification of unknowns. Anal Bioanal Chem 2010, 397, (3), 943-951.

10. Chiaia-Hernández, A. C.; Günthardt, B. F.; Frey, M. P.; Hollender, J., Unravelling Contaminants in the Anthropocene Using Statistical Analysis of Liquid ChromatographyHigh-Resolution Mass Spectrometry Nontarget Screening Data Recorded in Lake Sediments. Environmental Science \& Technology 2017, 51, (21), 12547-12556.

11. AWA, Amt für Wasser un Abfall. Zustand der Kleinseen.

https://www.bve.be.ch/bve/de/index/wasser/wasser/gewaesserqualitaet/Seen.assetref/dam/d ocuments/BVE/AWA/de/GBL/SeenDivers/GBL_Kleinseen_2003.pdf. Accessed on 15.06.2020. In 2015.

12. Appleby, P. G., Three decades of dating recent sediments by fallout radionuclides: a review. The Holocene 2008, 18, (1), 83-93.

13. Tu, L.; Zander, P.; Szidat, S.; Lloren, R.; Grosjean, M., The influences of historic lake trophy and mixing regime changes on long-term phosphorus fractions retention in sediments of deep, eutrophic lakes: a case study from Lake Burgäschi, Switzerland. Biogeosciences Discuss. 2019, 2019, 1-25.

14. Appleby, P. G., Chronostratigraphic Techniques in Recent Sediments. In Tracking Environmental Change Using Lake Sediments: Basin Analysis, Coring, and Chronological Techniques, Last, W. M.; Smol, J. P., Eds. Springer Netherlands: Dordrecht, 2001; pp 171203.

15. Carroll, J.; Lerche, I., Sedimentary Processes: Quantification Using Radionuclides. Elsevier: 2003; Vol. 5.

16. Tylmann, W.; Fischer, H. W.; Enters, D.; Kinder, M.; Moska, P.; Ohlendorf, C.; Poręba, G.; Zolitschka, B., Reply to the comment by F. Gharbi on "Multiple dating of varved sediments from Lake Łazduny, northern Poland: Toward an improved chronology for the last 150 years". Quaternary Geochronology 2014, 20, 111-113.

17. von Gunten, L.; Grosjean, M.; Beer, J.; Grob, P.; Morales, A.; Urrutia, R., Age modeling of young non-varved lake sediments: methods and limits. Examples from two lakes in Central Chile. Journal of Paleolimnology 2009, 42, (3), 401-412. 
18. Appleby, P. G.; Oldfield, F., The calculation of lead-210 dates assuming a constant rate of supply of unsupported $210 \mathrm{~Pb}$ to the sediment. CATENA 1978, 5, (1), 1-8. 
686

687

688

689

690

691

692

693

694

695

696

697

698

699

700

701

702

703

704

705

706

707

708

709

710

711

712

713

714

715

716

717

718

719

720

721

722

723

724

725

726

727

728

729

730

731

732

733

734

735

736

737

738

739

35. Lazartigues, A.; Fratta, C.; Baudot, R.; Wiest, L.; Feidt, C.; Thomas, M.; Cren-Olivé, C., Multiresidue method for the determination of 13 pesticides in three environmental matrices: water, sediments and fish muscle. Talanta 2011, 85, (3), 1500-1507.

36. Masiá, A.; Campo, J.; Vázquez-Roig, P.; Blasco, C.; Picó, Y., Screening of currently used pesticides in water, sediments and biota of the Guadalquivir River Basin (Spain). Journal of Hazardous Materials 2013, 263, 95-104.

37. Massei, R.; Byers, H.; Beckers, L.-M.; Prothmann, J.; Brack, W.; Schulze, T.; Krauss, M., A sediment extraction and cleanup method for wide-scope multitarget screening by liquid chromatography-high-resolution mass spectrometry. Anal Bioanal Chem 2018, 410, (1), 177-188.

38. Smalling, K. L.; Kuivila, K. M., Multi-residue method for the analysis of 85 current-use and legacy pesticides in bed and suspended sediments. Journal of Chromatography A 2008, 1210, (1), 8-18.

39. FOEN Water quality in Lakes. Federal Office for the Environment. Switzerland. https://www.bafu.admin.ch/bafu/en/home/topics/water/info-specialists/state-ofwaterbodies/state-of-lakes/water-quality-in-lakes.html. Accessed on 15.06.2020.

40. Håkanson, L.; Jansson, M., Principles of Lake Sedimentology. Blackburn Press: 1983.

41. Kiefer, K.; Müller, A.; Singer, H.; Hollender, J., New relevant pesticide transformation products in groundwater detected using target and suspect screening for agricultural and urban micropollutants with LC-HRMS. Water Research 2019, 165, 114972.

42. Postigo, C.; Barceló, D., Synthetic organic compounds and their transformation products in groundwater: Occurrence, fate and mitigation. Science of The Total Environment 2015, 503-504, 32-47.

43. Herrero-Hernández, E.; Andrades, M. S.; Álvarez-Martín, A.; Pose-Juan, E.; Rodríguez-Cruz, M. S.; Sánchez-Martín, M. J., Occurrence of pesticides and some of their degradation products in waters in a Spanish wine region. Journal of Hydrology 2013, 486, 234-245.

44. PPDB: Pesticide Properties DaraBase. Agriculture \& Environment Research Unit (AERU) at the University of Hertfordshire. https://sitem.herts.ac.uk/aeru/ppdb/en/index.htm. Accesed on 02.072019.

45. Kreuger, J., Pesticides in stream water within an agricultural catchment in southern Sweden, 1990-1996. Science of The Total Environment 1998, 216, (3), 227-251.

46. Simon-Delso, N.; San Martin, G.; Bruneau, E.; Hautier, L., Time-to-death approach to reveal chronic and cumulative toxicity of a fungicide for honeybees not revealed with the standard ten-day test. Scientific Reports 2018, 8, (1), 7241.

47. Cohen, S. Z., Urban pesticide risk assessment and risk management: Get involved. Environmental Toxicology and Chemistry 2010, 29, (6), 1201-1202.

48. Wan, H. B.; Wong, M. K.; Mok, C. Y., Pesticides in Golf Course Waters Associated with Golf Course Runoff. Bulletin of Environmental Contamination and Toxicology 1996, 56, (2), 205-209.

49. Baris, R. D.; Cohen, S. Z.; Barnes, N. L.; Lam, J.; Ma, Q., Quantitative analysis of over 20 years of golf course monitoring studies. Environmental Toxicology and Chemistry 2010, 29, (6), 1224-1236.

50. Holder, P. J.; Jones, A.; Tyler, C. R.; Cresswell, J. E., Fipronil pesticide as a suspect in historical mass mortalities of honey bees. Proceedings of the National Academy of Sciences 2018, 115, (51), 13033-13038.

51. BLW, List of Approved Plant Protection Products. Federal Office for the Agriculture. https://www.psm.admin.ch/de/produkte. Accessed on 03.03.2020. In 2018.

52. Creusot, N.; Casado-Martinez, C.; Chiaia-Hernandez, A.; Kiefer, K.; Ferrari, B. J. D.; Fu, Q.; Munz, N.; Stamm, C.; Tlili, A.; Hollender, J., Retrospective screening of highresolution mass spectrometry archived digital samples can improve environmental risk assessment of emerging contaminants: A case study on antifungal azoles. Environment International 2020, 139, 105708. 
740 53. AG20191206_Ecotoxicité des sédiments de ruisseaux. Aqua and Gas.

741 https://www.aquaetgas.ch/fr/eau/cours-d-eau/ag20191206 ecotoxicit\%C3\%A9-des-

742 s\%C3\%A9diments-de-ruisseaux/. Accessed on 01.05.2020.

743 54. Zhao, H.; Li, K.; Wu, S.; Wu, C.; Xu, H.; Hu, X.; Wu, M., Evaluation on toxicity and

744 safety of chlorpyrifos to environmental organisms. Acta Agriculturae Zhejiangensis 2004, 16,

745 (5), 292-298.

746 55. Doe, K.; Burt, G. R.; Ho, K., Porewater toxicity testing: An overview.

747 https://cfpub.epa.gov/si/si_public_record_Report.cfm?Lab=NHEERL\&dirEntryld=115244.

748 Accesed on 01.05.2020. In 2003.

749 56. Ochsenbein, U.; Berset, J. D.; Scheiwiller, E., Mikroverunreinigungen in Bernischen

750 Gewässern. Aqua and Gas 2015, 2, 56-66.

751 57. Song, N. H.; Yin, X. L.; Chen, G. F.; Yang, H., Biological responses of wheat (Triticum

752 aestivum) plants to the herbicide chlorotoluron in soils. Chemosphere 2007, 68, (9), 1779-

7531787.

754 58. NORMAN Substance Database - NORMAN SusDat. https://www.norman-

755 network.com/nds/susdat/. Accesed on 17.07.2019. 